\title{
Non-invasive Techniques of Fetal Diagnosis and Therapy in Perinatal Medicine
}

\section{Kazuo Maeda*}

Department of Obstetrics and Gynecology (Emeritus), Tottori University Medical School, Yonago, Japan

\begin{abstract}
Aims: Invasive techniques in fetal diagnosis and therapy are gradually changing to noninvasive methods, which would be presented in this article as well.

Methods: Noninvasive methods in fetal diagnosis are reviewed

Results: External ultrasonic Doppler autocorrelation fetal monitor; ultrasonic Doppler fetal actocardiogram; ultrasonic 2D, 3D, 4D imaging methods, pulsed Doppler blood flow record, color and power Doppler flow mappings, gray level histogram width method in the prediction of neonatal RDS in preterm fetal lung; other tissue characterization techniques and recent noninvasive prenatal test (NIPT) in fetal diagnoses, high intensity focused ultrasound ablation for the TRAP sequence in monochorionic twins in fetal therapy were presented.
\end{abstract}

Conclusion: Noninvasive methods were introduced to fetal studies to perform fetal diagnosis and therapy safely.

Keywords: Non-invasive methods; Perinatal medicine; Ultrasound; Fetal behavior: Fetal heart rate monitoring; Fetal lung immaturity diagnosis; Ultrasonic tissue characterization; Gray level histogram width; Periventricular echodensity; PVL; TRAP; High intensity focused ultrasound therapy

\section{Introduction}

There have been many diagnostic techniques using amniotic fluid or placental villi, for which needed puncture of amniotic fluid (amniocentesis) and placental villi sampling (CVS) in early pregnancy. The techniques accompany some risk factors of fetal demise or miscarriage. Also immature fetal lung was diagnosed in preterm births by the chemical or physical property of amniotic fluid obtained by amniocentesis. Some fetal aneuploidies diagnosed by amniocentesis and chorionic villi sampling (CVS), are now changing to noninvasive prenatal test (NIPT). Fetal heart rate was monitored by invasive direct fetal electrode without monitoring fetus during pregnancy, changed noninvasive external method. Fetal movement observed by real-time B-mode was changed to ultrasonic Doppler actocardiogram. Most fetal therapies were performed under invasive techniques, while recent trends are non-invasive techniques as seen in this chapter.

\section{Non-invasive fetal diagnosis}

Fetal heart rate (FHR) monitoring: Originally fetal heart beats were monitored by listening fetal heart tones using obstetric stethoscope. It was hard in the labor, almost impossible and fetal life was unclear immediately before fetal delivery, and the useful FHR signs were unable to detect by the fetal heart tones listening, consequently fetal demise, neonatal asphyxia were frequent before introduction of electronic fetal monitoring, which was done by invasive needle or spiral metal electrodes penetrating fetal scalp skin, which was contraindicated in pathological virus and bacterial infection of the mother due to vertical fetal infection [1]. In addition, the scalp electrode and the intrauterine pressure for uterine contraction were unable in pregnancy. Hammacher and Gentner [2] in Germany and Maeda [3] in Japan were unique because they used fetal heart sound microphone for the FHR tracing and external method for uterine contraction. Ultrasonic Doppler fetal heart signal and autocorrelation FHR meter [4] after the establishment of ultrasound safety [5,6], external FHR monitoring has been widely utilized. Maeda [7] added ultrasound Doppler fetal movement recording (actocardiogram, ACG) enabling to use single ultrasonic probe for FHR and fetal movement records. Fetal resting state, non-reactive FHR and hiccupping are diagnosed, physiological sinusoidal FHR is differentiated from ominous sinusoidal FHR, and fetal outcome is quantitatively determined, after fetal movement is added in the actogram. The ultrasound is safe in the ACG, because it uses only $1 \mathrm{~mW} / \mathrm{cm}^{2}$ continuous wave ultrasound in Japan.

Ultrasound imaging: The ultrasound is representative for the noninvasive diagnostic techniques, and the most useful in the imaging of the fetus, fetal membrane, placenta, umbilical cord, blood flow, by the real-time $2 \mathrm{D}, 3 \mathrm{D}, 4 \mathrm{D}$ ultrasound, echocardiography, pulsed Doppler methods, color- and power Doppler flow mapping, from the sonoembryology, genetic fetal ultrasound, to the fetus passing through the pelvis in the delivery $[8,9]$. Fetal $2 \mathrm{D}, 3 \mathrm{D}$ and $4 \mathrm{D}$ ultrasound are presented in the topics of this special issue. Noninvasive prenatal test (NIPT) studies maternal peripheral blood to detect fetal DNA in the blood to diagnose fetal 13,18 and 21 trisomies in noninvasive technique to the fetus with high sensitivity and high negative predictive value [10]

Immature fetal lung prediction by ultrasonic tissue characterization: The immature fetal lung was predicted by the analysis of chemical and physical properties of amniotic fluid obtained by amniocentesis, while immature fetal lung tissue of preterm fetus was diagnosed by ultrasonic gray level histogram with (GLHW) value, an ultrasonic tissue characterization created by Maeda [11], and the lung immaturity followed by neonatal respiratory distress syndrome (RDS) is diagnosed by the GLHW before delivery without amniocentesis, i.e.,

*Corresponding author: Kazuo Maeda, Department of Obstetrics and Gynecology (Emeritus), Tottori University Medical School, Yonago, Japan, 3-125, Nadamachi, Yonago, Tottoriken, 683-0835, Japan, Tel: 81-859-22-6856; Fax: 81-859-22-6856 E-mail: maedak@mocha.ocn.ne.jp

Received April 23, 2013; Accepted May 28, 2013; Published June 02, 2013

Citation: Maeda K (2013) Non-invasive Techniques of Fetal Diagnosis and Therapy in Perinatal Medicine. J Health Med Informat S11: 011. doi:10.4172/2157. 7420.S11-011

Copyright: ( 2013 Maeda K. This is an open-access article distributed under the terms of the Creative Commons Attribution License, which permits unrestricted use, distribution, and reproduction in any medium, provided the original author and source are credited. 
$96 \%$ of neonatal RDS was predicted by the product of fetal lung GLHW and gestational weeks [12]. Invasive diagnosis of immature fetal lung by the amniocentesis may be replaced by the GLHW diagnosis. The GLHW is the length of ultrasonic gray level histogram width divided by full length of brightness. And the GLHW value is displayed by "\%w" sign index in the histogram analysis on the monitor display of Aloka B-mode machines [11].

The other application of GLHW diagnosis: The fibrin deposition of intervillous space was diagnosed by the high placental GLHW in a fetal growth restriction (FGR) case in mid pregnancy where the fetus in previous pregnancy died due to FGR, was treated by 5,000 U Heparin every day by Utsu et al. [11]. The GLHW value became low, fetal growth recovered and normal baby was born in late pregnancy with normal birth weight.

Fetal brain periventricular echo density (PVE) which was the white zone around the ventricle as bright as or brighter than choroid plexus, showed high GLHW than normal brain, where 18 percent of persistent PVE until preterm birth accompanied neonatal periventricular leukomalacia (PVL) and cerebral palsy (CP) [13]. Therefore, a preterm birth infant who shows PVE at the day of birth should be treated and erase the PVE to reduce congenital CP.

Meconium stained amniotic fluid was differentiated from normally clear fluid by the high GLHW by Maeda without amniocentesis nor amnioscopy [14].

In gynecology, in five connected regions of interest (ROI) of ovarian masses, malignant ovarian tumors showed higher GLHW and lower coefficient of variation than benign ovarian masses [14]. In endometrial cancer, GLHW showed higher value than benign endometrial hyperplasia [15]. The malignant tissue is possibly detected by GLHW.

1. Non-invasive fetal therapy by high intensity focused ultrasound (HIFU). Ichizuka K et al [16] intended to treat the twin reversed arterial perfusion (TRAP) sequence for the purpose of diminishing cardiac burden in the normal pump fetus. There was a monochorionic twin of normal fetus who is connected to an acardiac acrania twin with umbilical cord containing artery to foster the acardiac twin. The heart of normal pumping twin must output large amount of blood to foster acardiac twin. The big problem is the death of acardiac twin due to effect of dead tissue on the normal twin. Therefore, several trial of separation of the acardiac twin by the ligation, fetoscopic ablation, raiofrequency ablation of the connecting cord between the twins in the amniotic fluid by opening the uterus or inserting instruments into amniotic cavity through the uterine wall, but it was dangerous to the pumping normal twin, and risky to injure the uterus or rupture the membrane.

Ultrasound warms biological tissues when it is absorbed by the exposed tissue. Therefore, the heating was avoided to the safety of diagnostic ultrasound, but the intense heating is the purpose to increase therapeutic effect in the ablation of connecting vessel in the TRAP sequence. Therefore, the first work was increase the output power of ultrasound in special generator. The ultrasound is focused to increase the intensity to 100 watts $/ \mathrm{cm}^{2}$ at the focus point to ablate the tissue. The ultrasound beam must not heat the tissue of the path of ultrasound propagation, particularly on the normal pumping twin, therefore ultrasound beams are concentrated to small focus, where the high temperature is produced in narrow focus. The machine will be carefully handled to concentrate the ultrasound to the subject. The amniotic fluid in the uterine cavity is a good ultrasound propagating material to avoid the heating of normal twin, placenta and maternal tissue at the same time to heat the subject. The focusing may be supported by the ultrasonic imaging at the subject. In the first case, ultrasound intensity was increased because initial intensity was insufficient, so that the tissue at the focused point showed degeneration [16]. Further case similar to initial one will be treated by HIFU in more cases, because of its noninvasive nature. The technique is promising in the fetal therapy in the concealed amniotic cavity.

\section{Conclusion}

Recent trend is non-invasive technique in fetal diagnosis and therapy, to promote the progress of perinatal medicine without damaging the fetus. Amniocentesis used to collect the amniotic fluid for the diagnosis of chemical and physical properties of the fluid will be replaced by ultrasonic tissue characterization, and non-invasive diagnosis is also useful for the repeated tests, e.g., to estimate the effect of steroid therapy for preterm fetuses. Furthermore, genetic fetal diagnosis will be performed by the test of maternal peripheral blood in NIPT, instead of the amniocentesis. Non-invasive fetal therapy was a dream in the past, and it is real at present by the HIFU technology. Perinatal medicine will be further progressed, opening new era of fetal medicine by non-invasive methods in the future.

\section{References}

1. Maeda K (1997) Report of the FIGO Study Group on the assessment of new technology. International Journal of Gynecology \& Obstetrics 59: 169-173.

2. Gentner O, Hammacher K (1967) An improved method for the determination of the instantaneous fetal heart frequency from the fetal phonocardiogram. Proc VII Intern Conf Med Biol Eng 140.

3. Maeda K (1965) Studies on the cardiotachography during labor. Proc.VI Intern Conf Med Elect Biol Eng 514-515

4. Takeuchi Y, Hogaki M (1977) Autocorrelation method for fetal heart rate management from ultrasonic Doppler fetal signal. Ultrasound in Medicine Vol 3B Engineering aspects. Plenum Press, New York 1327-1332.

5. Maeda K, Murao F, Yoshiga T, Yamauchi C, Tsuzaki T (1986) Experimental studies on the suppression of cultured cell growth curves after irradiation with CW and pulsed ultrasound. IEEE Transactions UFFC 33: 186-193.

6. Maeda K, Ide M (1986) The limitation of the ultrasound intensity for diagnostic devices in the Japanese Industrial Standards. IEEE transactions UFFC 33 241-244.

7. Maeda K (2004) Fetal monitoring and actocardiogram in the evaluation of fetal behavior. The Ultrasound Review of Obstetrics and Gynecology 4: 12-25.

8. Barbera AF, Imani F, Becker T, Lezotte DC, Hobbins JC (2009) Anatomic relations between the pubic symphysis and ischial spines and its clinical significance in the assessment of fetal head engagement and station during labor. Ultrasound Obstet Gynecol 33: 320-325.

9. Henrich W, Dudenhausen J, Fuchs I, Kämena A, Tutschek B (2006) Intrapartum translabial ultrasound (ITU): sonographic landmarks and correlation with successful vacuum extraction. Ultrasound Obst Gynecol 28: 753-760.

10. Hall A, Bostanci A, Wright CF (2010) Non-invasive prenatal diagnosis using cell-free fetal DNA technology:applications and implications. Public Health Genomics 13: 246-255.

11. Maeda K, Utsu M, Kihaile PE (1998) Quantification of sonographic echogenicity with grey level histogram width: a clinical tissue characterization. Ultrasound Med Biol 24: 225-234.

12. Serizawa M, Maeda K (2010) Noninvasive fetal lung maturity prediction based on ultrasonic gray level histogram width. Ultrasound Med Biol 36: 1998-2003.

13. Yamamoto N, Utsu M, Serizawa M, Murakoshi T, Maeda K, et al. (2000) Neonata periventricular leukomalasia predeed by fetal periventricular echodensity. Fetal Diagn Ther 15: 198-208.

14. Maeda K (2011) Fetal diagnosis with ultrasonic actocardiogram and GLHW tissue characterization. Donald School J Ultrasound Obstet Gynecol 5: 167. 
Citation: Maeda K (2013) Non-invasive Techniques of Fetal Diagnosis and Therapy in Perinatal Medicine. J Health Med Informat S11: 011. doi:10.4172/2157-7420.S11-011

Page 3 of 3

15. Maeda K, Yamamoto N, Ito T, Serizawa, M, Utsu M, et al. (2002) Clinical tissue characterization with gray level histogram width in obstetrics and gynecology. The Ultrasound Review of Obstetrics \& Gynecology 2: 124-128.
16. Ichizuka K, Aoki H, Ichihara M, Matsuoka R, Hasegawa J, et al. (2008) Application of high-intensity focused ultrasound for fetal therapy: experimental study using animal model of lower urinary tract obstruction. Journal of Medical Ultrasonics 32: 107-110. 